\title{
The state of science and technology infrastructure in secondary schools in Nigeria
}

\author{
Nwachukwu Uche Emma \\ Governance Policy Research Department, Nigerian Institute of Social and Economic Research,
} PMB 5, UI Post Office, Ibadan, Nigeria

E-mail address: emannuelnwachukwu@yahoo.com

\begin{abstract}
Science and technology (S\&T) education is crucial to the development of any society and also a critical element in the attainm Goals (MDGs). Standard laboratories and equipments as well essential for providing qualitative education for producing nat evaluates the condition of S\&T infrastructures in the Nig trian secondary so ools. The study utilises primary data collected from public and private secondar schools across the six geo-political zones in the country. Findings show that there are inadequate teac s, laboratori s and necessary equipment for teaching S\&T related subjects in most of the secondary sch in Nige la. Also, electricity supply from the national grid to secondary schools is poor ouse only them have light at most 4 hours a day. The study therefore recommends the prov lo. dequate funds and electricity generators for these institutions to enhance the teaching and or rall den pment of S\&T education in Nigeria. In addition, adequate and qualified persomel (teach s and laboratory technicians) should be provided while good maintenance culture ar $1 \mathrm{~m}_{\mathrm{m}}$ ved sec rity of laboratories and equipment in secondary schools should be imbibed by all onda) schools i, the country.
\end{abstract}

Keywords: Science and tec' nology; in tructure; Nigeria

\section{INTROD' CTIO}

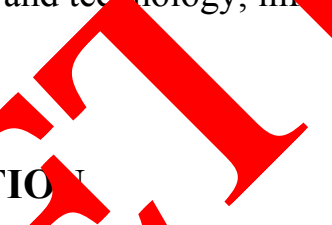

1. 1. Backgrou o the $S$ dy

oclu and $\mathrm{e}$ alogy (S\&T) has been globally recognised as major instrument of ec mic evelopment and social transformation. As a result, every nation has continued to pursu ledge in order to remain relevant in a globalised world economy. A major source 0 KT knowledge and skills are educational institutions at all levels. The purpose of education to generate and apply knowledge resulting in improvements in science and technology, while the S\&T infrastructures required for knowledge generation and the attendant learning processes are the lifeline of the educational system. The state of available S\&T infrastructures in educational institutions is a determinant factor of the capacity of the educational system to produce the requisite human capital necessary for achieving competitive economy and social transformation.

The production of adequate and competent technological manpower is a major challenge in Nigerian education industry. The education industry in the country has been battling with various aspects of infrastructure development challenges for improving the quality of education 
and expanding access. The various government efforts to improve infrastructure in educational institutions include construction of classrooms, lecture halls, laboratories and staff quarters as well as supply of water and electricity to improve quality of education and manpower production.

This study examines the condition of S\&T infrastructure in secondary schools in Nigeria. The study aims to contribute to the attainment of Nigeria's Vision 20:2020 and socio-economic transformation agenda currently pursue by the Federal Government of Nigeria (FGN).

\section{2. Problem Statement}

It is generally acknowledged that the delivery of education in Nigeria has uffered $\mathrm{h}$ many years of neglect. This led to frequent industrial actions by trade unions education institutions and students unrests caused by discontent arising from poor of cotion infrastructure.

Again, the various efforts to address the challenges of educatio infra uruct re rude establishment of model schools, creation of specialised colleges blis ent of ow public and private secondary schools. Other efforts included the estab ${ }^{1}$ ment of $s_{1}$ ia sed funding support for infrastructure from donor agencies and local insti tion as the ducation Trust Fund (ETF) and the Universal Basic Education Commissio NBEC) ong others. The extent to which these mechanisms support or contribute to th development o \& $\mathrm{T}$ infrastructure in
the educational system has been unclear.

In addition, investment in S\&T infrastructur still remail a factor not raised to the forefront when considering issues of educational de vment Nigeria, and where it does, such investment is often subsumed under go infrastimnue items. Currently, the quality of education provided remains grossly deficient naw to build the human capital required for a competitive economy.

\subsection{Research Questions}

The research question da. study are:

a) What is the cur tate of So infrastructure in secondary schools in Nigeria?

b) What are the nnst s and op ortunities for the development of S\&T infrastructure in secondary hools in country?

c) What a the cessary $p$ cies that will enhance the development of S\&T infrastructure in se tary scroo s in Nigerian?

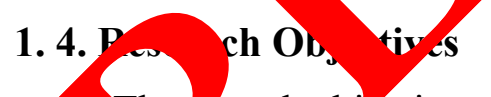

The road objective of this study is to examine the state of S\&T infrastructure in secon scruou in Nigeria. The specific objectives are to:

a) ex. Ae the current state of S\&T infrastructure in secondary schools in Nigerian;

b) identify the constraints and opportunities for the development of S\&T infrastructure in secondary schools in Nigerian; and

c) Make policy recommendations on how the develop S\&T infrastructure in Nigerian secondary schools. 


\section{5. Justification for the Study}

Nigeria is technologically poor due to poor investment in human capacity development and necessary infrastructure. Presently, the 60:40 ratio of students' admission into science and art disciplines in tertiary institutions is yet to be achieved in the country.

This study becomes necessary in order to foster national technology capability building. Besides, it is unknown whether any study has examined the state of S\&T infrastructure in secondary schools in Nigeria. This study aimed at bridging this knowledge gap and also proffers policies and actions that will enhance availability of S\&T infrastructure in Nigerian secondary schools.

\section{LITERATURE REVIEW}

\section{1. The Meaning and Role of Science and Technology Infrastruct re \\ Science and Technological Infrastructure can generally be de atermed ate inputs} that provide the basis for the functioning of other technologies provide $\mathrm{n}$ tio services to other sectors of the economy. Technology infrastructure thy co ts of scie e, engineering and technical knowledge available to industry. Such kno alge ca embodied in human, institutional, or facility forms. More specifically, tec nology infrast áre includes generic technologies, technical information, and research an test facilities, as twell as less technically explicit areas including information relevant for stra vic plannin and market development.

Science and Technology infrastructures amo others are some of the minimum requirements that feed into technological an industria opment of any economy. Tassey (1992) describes Science and Technological thr. engineering and technological knowledge ava $\mathrm{ab}^{1}$ to to vate industry ... embodied in human, institutional or facility forms'. He ${ }^{\prime}$ 'udes th at national and firm levels respectively, there is an increasingly dependence $g$ serv deliver of Science and Technology Infrastructure.

The role of Science ara hn an engine of development is an emerging issue that is bec nmmg ature prominently on the Nigerian scene. This is being demonstrated aptly in Nationa lycation and also National S \& $\mathrm{T}$ policies and in subsequent econom de pments and reform framework of the country. The current economic reform amework the Vision 20:2020 (NV20:2020), and it features S \& T infrastructure as a o oss-cuttin assue that has to be promoted in order to achieve economic developmen. iecti esv(NPC, 2007).

The state povert in the country and the challenge of meeting the Millennium Devel P. Goa in ais respect, in particular have drawn attention to the role of $\mathrm{S} \& \mathrm{~T}$ inf truct $e$ for soly cons of technological adaptation and diffusion based on local conditions and $\quad$ example those that can boost agricultural productivity and food storage capacit duce post-harvest losses, promote renewable energy (including bio-fuels and solar), develop ra Vater harvesting systems, deliver potable water to rural villages, and improve basic health care.

\section{2. The Role and Importance of Science Laboratories}

At every level of science education, laboratories are perceived as a vehicle for curriculum enhancement. Studies including Hadley \& Rheingold, 1992; McDaniel, Melnerney \& Armstrong, 1993; Hannafin \& Saverye, 1993) have indicated that a properly equipped and functional science laboratory has the potential for enhancing science learning. Science 
laboratories have a central and distinctive role in S\&T education, and science educators suggest that there are rich benefits in learning from using laboratory activities.

In many African countries, research has revealed shortages in the number of laboratories in schools. A study by Jones (1990) found that $45 \%$ of the schools surveyed in selected African countries indicated insufficient laboratories. Alebiosu, 2000 and Onipede, 2003 reported that many schools in Nigeria do not have laboratory with minimum standard facilities. This finding agreed with Barrow`s (1991) findings in Saudi Arabia which also indicated inadequacy in the provision of laboratory facilities in schools.

The findings were also consistent with those of Black et al. (1998) who found in I I anda that science education is faced with the problem of lack of resources with hal the sc having no real laboratory. Leister, (1992) observed that shortages of laboratory cilities co have serious implications on the quality of schools` output.

\section{METHODOLOGY}

\section{1. Primary Data Collection and Scope of Study}

This study covered both the private and public second. y sch in selected states in the six geopolitical zones of Nigeria. The choice of the secen schoo anchored on the fact that it is at these levels that education become profo and and learning s tailored to breeding future physicians, scientists, engineers, technicians a other profe sionals. The choice of states for the study is based on investment in $S \& T$ inf tucture in the educational sector, and availability of the frame/list of public and private tertia. 2010.

\section{2. Sample Selection}

One state was selected in er the $s$ geo-political zones for the study. Based on perceived performance on inves ment educati with focus on S \& T infrastructure in 2010, one state was selected from eac th thenolizical zones as follows:

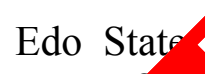

$$
\text { Enugu stá. }
$$

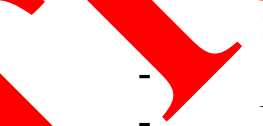

South-South

South-East

North-West

North-Central

South-West

North-East

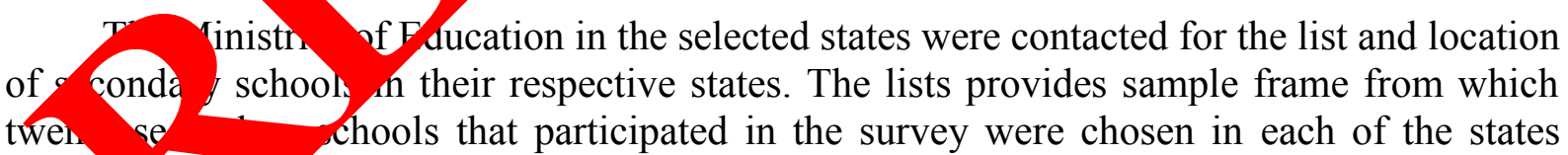
selecte The secondary schools were stratified into public and private secondary schools, and urban and al secondary schools. Secondary schools located in the state capital and local government headquarters were generally regarded as urban schools while those elsewhere were regarded as rural schools.

There are two types of semi-structured questionnaires employed as instruments for eliciting the primary data/information from respondents. One questionnaire was designed for secondary school principals and one for teachers of S\&T related subjects. In each secondary school, five questionnaires were administered. Altogether, 600 questionnaires were administered in secondary schools while 438 questionnaires were retrieved representing $73 \%$ 
retrieval rates. For the primary data collection, field research assistants were recruited and trained in each state served as enumerators.

The questionnaire aimed at collecting data on S\&T related issues such as nature of S\&T related investments in the educational sector, availability of teachers in S\&T related subjects, number and quality of S\&T laboratories available in the institutions, capability to use laboratory equipment, availability and adequacy of chemical reagents in the institutions, the availability and adequacy of S\&T equipment in the schools, the age and functionality of the available S\&T equipment and materials, the adequacy or otherwise of S\&T teaching materials and personnel and level of availability of water and electricity. To gain deeper insights into the constroints on S\&T infrastructure development and how to overcome them, interviews of director of resa planning and statistics in each of the selected state's ministry of education wer rried out.

\section{3. Data Analysis}

The Statistical Package for Social Science (SPSS) was used to following which descriptive statistics such as frequency counts, appropriate to explain the features of science and technolog frastructu in the sampled secondary schools. Chi-square was calculated to measure the iffe ce in sign cance between private and public educational institutions.+

\section{FINDINGS}

\section{1. State of Science and Technology Infrastructur.}

\section{1. 1. Human Capital Outlay}

An important determinant of economic $g$ th and development is human capital outlay. The quality and nature of educat on ermine he knowledge and skills available for human capital upgrading. From the fi ings the stud, three elements of the results provide some insights to the human capit ou suria educational sector. These are qualification of teachers of secondary schools; ntity and level of experience of teachers; and ratio of teachers to students.

\section{1. 2. Qualific cion of Teac.}

Table shoy he distribution of the highest qualifications of teachers in the sampled secondary scho $82 \% \mathrm{~g}$ the teachers have at least a bachelor degree in their subject areas, while $\mathrm{ND}$ or NCE in S\&T related subjects. In fact, about $91 \%$ of the teachers hay at lea HND or .S.S.

that very high proportion of teachers in S\&T related subjects have apprec requisite qualifications in S\&T subjects. It is often advocated that teachers in S\&T subjects st also possess training in education. From the results in Table 1, only $8.4 \%$ of the teachero have a postgraduate diploma in education and only $8.7 \%$ have national certificate in education. 
Table 1. Highest qualification of teachers in Nigerian secondary schools.

\begin{tabular}{|c|c|c|}
\hline Highest Qualification & Frequency & Percent \\
\hline NCE & 38 & 8.7 \\
\hline HND & 41 & 9.4 \\
\hline B.Sc. & 272 & 62.1 \\
\hline M.Sc. & 50 & 11.4 \\
\hline PGD & 37 & \\
\hline Total & $\mathbf{4 3 8}$ & \\
\hline Source: Field Survey, 2011 & &
\end{tabular}

Table 2 shows the teacher to students' ratio. T able sho that, there are 4,793 teachers in S\&T related subjects and 90,672 students This implies a te, cher to students' ratio of 1:19. Except for wood work and metal work, the acher to stu lents ratios are very poor in all the S\&T related subjects the most affected subject ing comp ter science and introductory technology with teacher to students ratios of 1:251 and 1 spectively. This shows that the quantity of teachers for S\&T related subject sampled secondary schools is inadequate.

Table 2. Teacher to students' ratio for sc related subjects in the research sample.

\begin{tabular}{|c|c|c|c|}
\hline & No. & $\begin{array}{c}\text { No. of } \\
\text { students }\end{array}$ & $\begin{array}{c}\text { Teacher to } \\
\text { students ratio }\end{array}$ \\
\hline Subject & 292 & 31124 & $1: 107$ \\
\hline B logy & 269 & 32897 & $1: 122$ \\
\hline Intro ory Te inology & 124 & 24881 & $1: 167$ \\
\hline Integra Science & 217 & 26938 & $1: 124$ \\
\hline Agricultural Science & 337 & 53725 & $1: 251$ \\
\hline Basic Electronics & 19 & 2241 & $1: 118$ \\
\hline Metal Work & 28 & 594 & $1: 21$ \\
\hline Wood Work & 93 & 588 & $1: 6$ \\
\hline
\end{tabular}

Source: Field Survey, 2011

From Table 3 showing the distribution of the subject areas of teachers' qualification, the vast majority $(71 \%)$ of the teachers are in the traditional science subject areas of chemistry, 
physics and biology. The remaining $31 \%$ of the teachers are distributed over other S\&T related subjects as shown in Table 3 . These results indicate that secondary school teachers' experiences are still mainly in basic science subjects comprising of chemistry, physics and biology.

Table 3. Subject area of teachers' qualification.

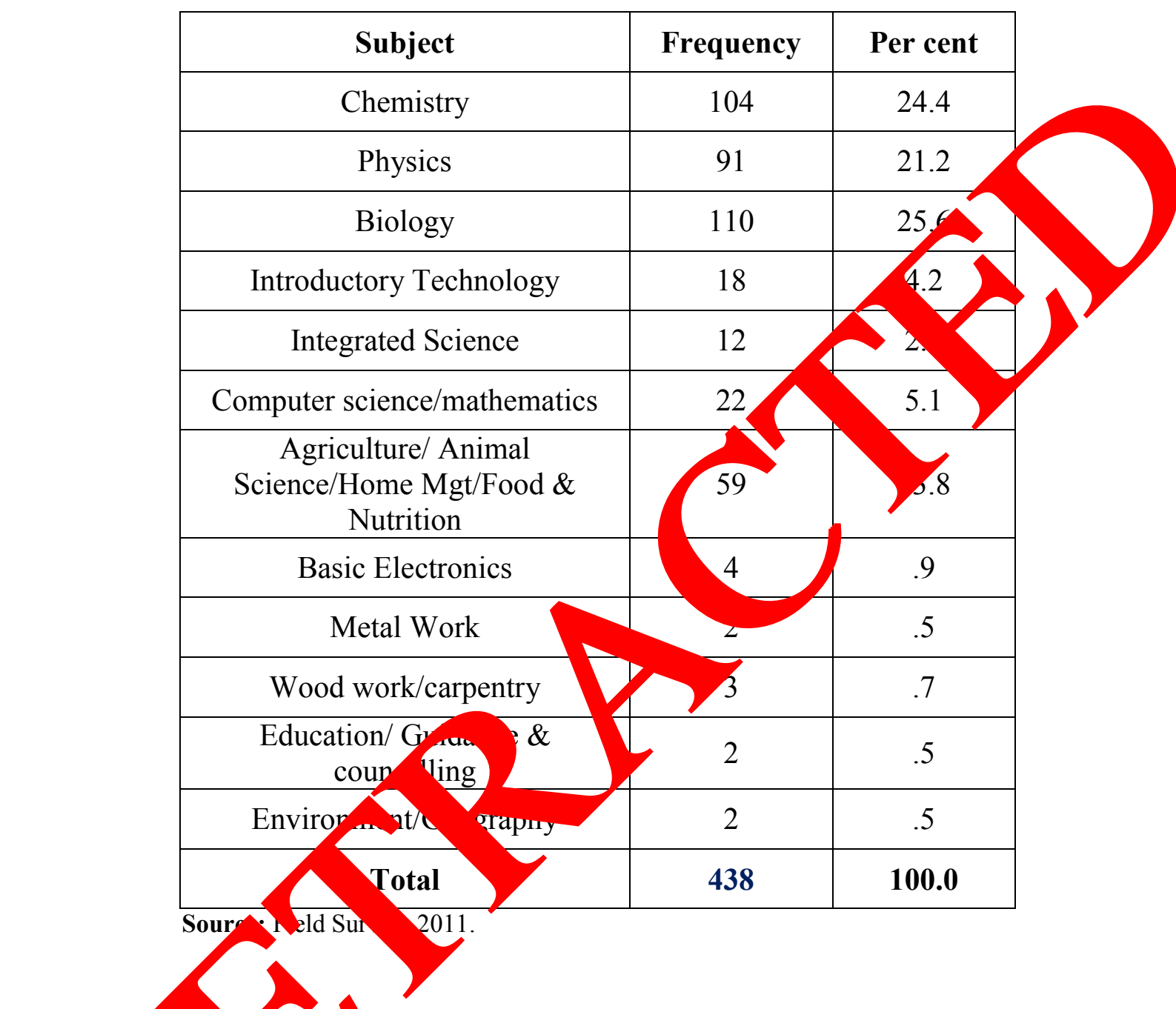

\section{2. Science a echnol by Hardware}

e and ology hardware in educational institutions is very crucial to the ad ceme $t$ of pr ctical teaching and learning. It includes the science laboratories, equip aching aids such as ICT facilities (computers, the Internet) as well as the suppor frastructure (electricity and water supply) which are expected to aid the best functioning 1 the science and technology hardware. Science laboratories, in particular have been found to be central to the teaching of science.

These laboratories are the workshops where practical activities are conducted to enhance a meaningful learning of science concepts and theories (Seweje, 2000; Olubor and Unyimadu, 2001).

\section{2. 1. Science Laboratories}

The results of our survey showed that $82.5 \%$ of schools in our study have between one and five science laboratories, while the remaining $17.5 \%$ have over five science laboratories. 
The minimum age of these laboratories is one year; while the maximum age is 30 years. About $55 \%$ of schools have laboratories within the age range 1 and 10 years old, while the remaining $45 \%$ are above 10 years old.

For each of the three core science subjects, which are Chemistry, Physics and Biology, over $90 \%$ of schools, claim to have separate laboratories. Furthermore, while $68.4 \%$, and 50 $\%$ have laboratories for agricultural science and introductory technology respectively. It was observed that integrated science and introductory science are often taken as the same subjects in many schools, and this may explain why only $39 \%$ claim to have a separate laboratory for integrated science. Figure 1 shows the responses received on the specific types of labomotories that exist in the schools in our sample. In addition to having specific laboratories almos 0 $\%$ of the schools attested to the fact that their schools have at least one science la atory, wh may be classified as multipurpose laboratory used for practical sessions fo a co ination subjects. The four most common combinations of subjects for which these mu urp se laboratories were used for, are as follows:

a. Chemistry, Physics, Biology Agriculture, Animal s, sme $\mathrm{Ma}$ agement, Food and Nutrition

b. Chemistry, Physics, Biology, Agriculture, Av nal ence, Hon c Management, Food and Nutrition and Basic Electronics

c. Chemistry, Physics, Biology, and Intro auctory Techno of/Integrated Science

d. Chemistry, Physics, Agriculture, Ar mal Science, Home Management, Food and Nutrition

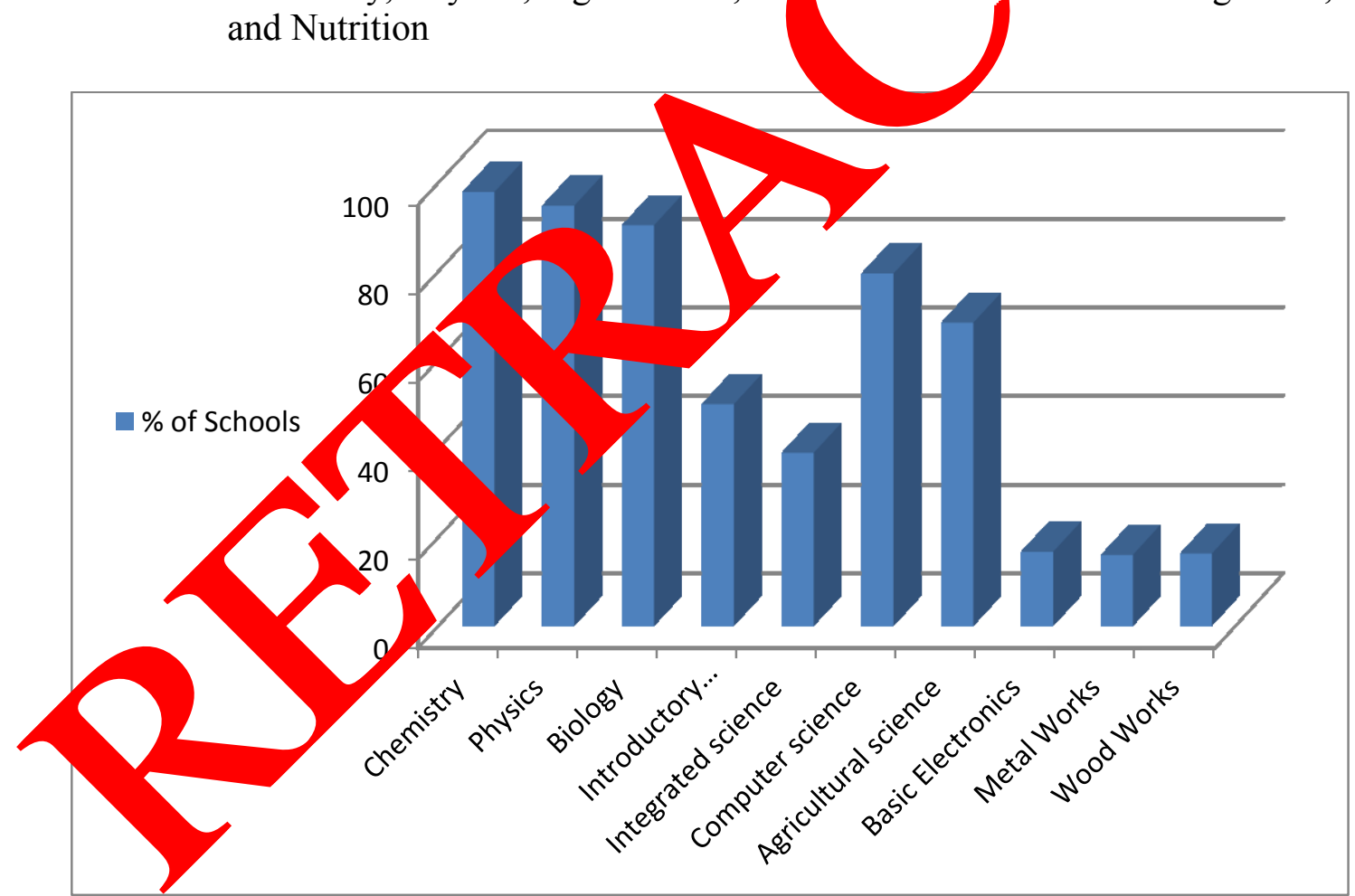

Source: Field survey, 2011.

Figure 1. Types of laboratories in Nigerian secondary schools.

\section{2. 2 Quality of Science Equipment}

Respondents were asked to rate how they perceived the quality of science equipments in the laboratories on a likert scale reported as poor $=1$, fair $=2$, good $=3$, very good $=4$ and 
excellent $=5$. The perception of respondents (see Table 4 ) show that about $35 \%$ perceive the equipment as good, while $12 \%$ perceive the equipments to be excellent, and $17.10 \%$ perceive them as poor.

Table 4. Perception on quality of science equipments.

\begin{tabular}{|c|c|c|}
\hline $\begin{array}{c}\text { Quality of science } \\
\text { equipment }\end{array}$ & $\begin{array}{c}\text { Secondary Schools } \\
\text { \% }\end{array}$ & Average \\
\hline Poor & 13.10 & 17.10 \\
\hline Fair & 25.60 & 18.05 \\
\hline Good & 34.80 & 35.80 \\
\hline Very Good & 18.40 & \\
\hline Excellent & 8.10 \\
\hline Source: Field survey 2011.
\end{tabular}

Further analysis was done based on the comp ation of the leve of significance of the perception levels on quality of equipments by teac rs in the p blic and private secondary schools. The results show that there is a significant cerence ir the perception on quality of equipment at secondary school level $\left(\mathrm{p}=0 . \mathrm{P}^{\circ 00)}\right.$.

\section{2. 3. Sources of Laboratory Reagents/Co suravy in Secondary Schools}

The main sources of labon reagen and consumables in the secondary school surveyed are the school (68.5\% and e State Jvernment (70.9\%). The PTA has not been active in this line of activity vith 10 schools reporting this trend.

\section{3. Electricity Supp}

Electricity sap y is of the factors that are likely to influence the functionality of science laborat ries, as it an o ntial input to many scientific processes. The regularity of electricity sy $\mathrm{y}$ fro $\mathrm{PHCN}$ (hational grid) to educational institutions is generally very poor. As shown in Ta abou $0 \%$ of schools have light for not more than 4 hours, and only 21.0 $5 \%$ of nden secondary education claim to have electricity from PHCN for more than 6 by not in re than curs per day.

Table 5. Regularity of electricity supply from PHCN.

\begin{tabular}{|c|c|}
\hline Regularity & Secondary schools \\
\hline Not more than 2 hrs & 29.9 \\
\hline $\begin{array}{c}\text { More than 2 but not more } \\
\text { than 4hrs per day }\end{array}$ & 29.9 \\
\hline $\begin{array}{c}\text { More than 4 but not more } \\
\text { than 6 hrs per day }\end{array}$ & 21.0 \\
\hline
\end{tabular}




\begin{tabular}{|c|c|}
\hline $\begin{array}{c}\text { More than } 6 \text { but not more } \\
\text { than } 8 \text { hrs per day }\end{array}$ & 7.6 \\
\hline $\begin{array}{c}\text { More than } 8 \text { but not more } \\
\text { than } 10 \text { hrs per day }\end{array}$ & 8.9 \\
\hline More than 10 hrs per day & 2.7 \\
\hline & $100 \%$ \\
\hline
\end{tabular}

Source: Field Survey, 2011.

With the results obtained on the regularity of electricity, it is therefore a to report that $74.1 \%$ of schools and $85.7 \%$ of faculties surveyed attest to th $\mathrm{yet}$ th hey ha e alternative sources of electricity power supply to their laboratories. T/e alt rnativ vu ces include electric generators, solar panels and inverters, as shown on $\mathrm{T} / 6$.

Table 6. Alternative sources of energy supply in Nig ran institut.

\begin{tabular}{|c|c|}
\hline Sources & Secona ry \\
\hline Electric Generator & \\
\hline Solar Panel & \\
\hline Inverter & \\
\hline
\end{tabular}

\section{4. Constraints To The Deve' pme Of S\& Ynfrastructure In Nigerian Educational Institutions}

All impediments the avan lity of viable and adequate S\&T infrastructure in the educational institution a constraints in this study. The general constraints identified to the de lopm of S\& infrastructure in secondary schools include lack of qualified laborz ory technicio inadequate laboratory equipment, poor to high quality reagents, poo electri ty supply and poor funding among others.

Analys the inte rews conducted on selected key officials in the respective State Ministriec visite lso $\mathrm{b}$ ghlighted some concerns on the constraints and suggestions for impr ven t of Sc, and Technology Infrastructures.

Thes responses are presented in Figure 2 and it shows that inadequate fund (100\%) was consic a as major constraint to the development of S\&T infrastructure in the education sector. 1 inadequate number of qualified teachers $(80 \%)$ and poor electricity supply $(60 \%)$ were repor $d$ by these officials as second and third constraints respectively. Other constraints were poor maintenance culture, poor management of funds and vandalisation of equipment (16.8\% respectively). 


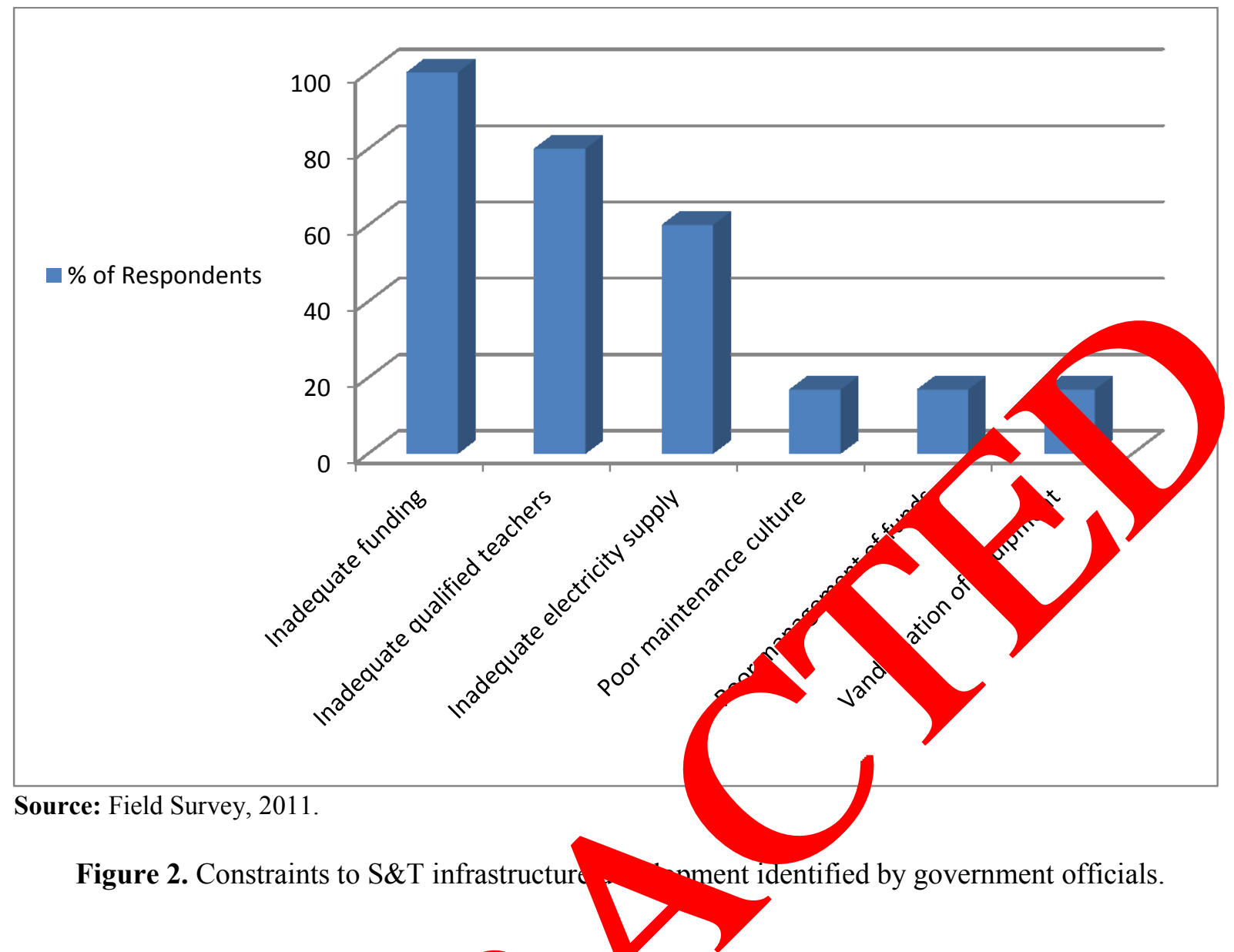

Results of the analysis car ea on the uggestions made by government officials to remove the constraints show $t^{\prime}$ ll $\mathrm{r}$. pondents (100\%) suggested improvement in the level of funding of education as ato way mproving S\&T infrastructure development. This was followed by the sug stion on $\mathrm{L}$ ing and re-training of teachers $(80 \%)$, procurement of electricity generating sets $\%$ imp ved security, proper management of funds and good maintenance cultu (bout $\angle$ respectively).

\section{CONCLOA S / RE OMMENDATIONS}

$\operatorname{Im}_{t}$ pved $\mathrm{Fu}_{\mathrm{u}}$ ing: To move Nigeria forward technologically, there is need to provide ad gents and equipment for secondary schools.

- P $\%$ of Necessary Amenities: There is a need for adequate and regular electricity supply and water supply to run the S\&T infrastructure in Nigerian Educational institutions. Electricity generators should be provided for the schools to complement power supply by the Power Holding Company of Nigeria (PHCN). All educational institutions should be provided with regular water supply from a well or borehole.

- Production of Qualified Personnel: Adequate and qualified personnel (teachers, laboratory technicians) should be provided in the Educational institutions. In addition, there is need to train and retrain these personnel to perform effectively. 
- Good Maintenance Culture and Proper Management of Funds: Good maintenance culture and improved security of school properties should be imbibed by all educational institutions. In addition, the provision and proper management of funds to source Science and Technology Infrastructure should be taken as a collective responsibility of the educational institutions, the state government, parents, and private individuals/organizations.

\section{References}

[1] Alebiosu K. A., Journal of Education Foundations Management 1 (2000) 64.

[2] Barrow L. H. (1991). Evaluation of Science Laboratories in the Middl ohoo Educational Districts in Saudi Arabia. PhD Thesis, University of M ssour Colun

[3] Black T. R., Atwaru-Okello D., Kiwanuka J., Serwadda D., Biy bi ' alinga Biumigishu A., Rodd A., Journal of Science Education 20 (1998) 249

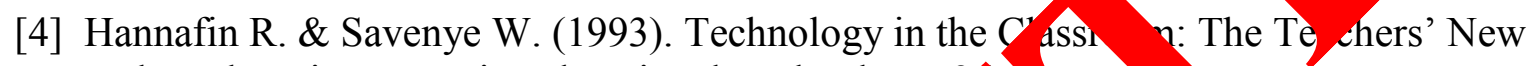
Role and Resistance to it. Educational Technology, 2

[5] Hadley M., Sheingold K., American Journal of E ucation 101 (199,) 261-315.

[6] Jones E., Journal of Science Education 140 (19 $\quad$ 27-27.

[7] Leister J. N. (1992). The Complexities of Practica ark in hysics Teaching: A Case Study of three Secondary Schools in Sic Teone. M.cu. Thesis, Queen's University at Kingston, Canada.

[8] McDaniel E., Melnerney W., Amatrong P. Educational Technology Research and Development 4191 (1993) 72,-78.

[9] NPC (2007). Nigeria: D ft mic Empowerment and Development Strategy-NEEDS2, N ational Ph ing Commission, Abuja.

[10] Olubor R. O., U yin S. (200).Management Demand for the Universal Basic Education Pr mme urrent Issues in Educational Management in Nigerian Associatio 1 for education cdministration and Planning (NAEAP). pp: 48-59.

[11] Onipea (2,0s). Tational Development Hinges on Quality Education. The Comet, January 2, 21.

[12] sewc R. O., o Mal of Education Foundations Management 1 (2000) 216-217.

[13] 32), Technology Infrastructure and Competitive Position, Kluwer A emic Publishers, Norwell 1992.

[14] Ardia Shingjergji, Besa Shingjergji, International Letters of Social and Humanistic Sciences 2 (2014) 56-66.

[15] Abubakar Aminu Boyi, International Letters of Social and Humanistic Sciences 3 (2014) 65-72. 